\title{
THE EFFECTS OF THE ENVIRONMENTAL CONDITIONS ON CURLED EXPRESSIVITY AND THE INTERACTION BETWEEN TWO MIMIC GENES, CURLED AND CURLY, IN DROSOPHILA MELANOGASTER
}

\author{
Ken Nozawa \\ Department of Animal Breeding, Faculty of Agriculture, Nagoya University, Anjo, Japan \\ Received July 13, 1956 \\ UDC $575.11: 575.24:$ \\ 595.772 .4 .
}

In a previous paper the author reported the influences of the environmental factors on Curly expressivity in Drosophila melanogaster (Nozawa, 1956). These factors were nutritional condition through the larval stage and cultural temperature in the last day of the pupal stage.

From the above study, the author sought to determine whether the expressivity of curled character could be controlled by the environmental conditions as in Curly. These two genes resemble one another phenotypically; however, curled is a completely recessive gene in the third chromosome, while Curly is of a dominant character accompanied with two large inversions in the second chromosome, and is lethal in the homozygous state. One purpose of the present investigation was to determine whether the environmental factors which influence the expressivity of Curly would affect also the phenotype of the curled gene; the other was to investigate the interaction between these mimic genes.

\section{Materials and methods}

A laboratory curled stock was used. For the experiments on the gene-interaction between curled and Curly, the genotypes of $\mathrm{Cy} / l ;+/+(\mathrm{Cy}+/+l ;++/++), \mathrm{Cy} /$ $l ; \mathrm{Sb} /+(\mathrm{Cy}+1+l ; \mathrm{Sb}+1++), \mathrm{Cy} / l ; \mathrm{Sb} / \mathrm{cu}(\mathrm{Cy}+1+l ; \mathrm{Sb}+/+\mathrm{cu})$ and $\mathrm{Cy} / l ; \mathrm{cu} / \mathrm{cu}(\mathrm{Cy}$ $+/+l ;+\mathrm{cu} /+\mathrm{cu})$ were used comparatively.

In order to describe the degree of curling appearance, the adult flies were classified into three types, "high," "intermediate" and "low," and the expressivity of a population was measured by the sum of the percentage of the "high" type and a half of the precentage of the "intermediate" type. The standards of the classification were as follows :

"high" type: Individuals having wings showing both cross and longitudinal wrinkles.

"intermediate" type: Individuals having wings showing only longitudinal wrinkles.

"low" type: Individuals showing a slight upward bend at the tip of the wings, including flies of the apparently wild type.

This method of measuring expressivity was the same used in the previous study on Curly expressivity. 
In all the experiments, the ordinary corn-meal-agar-media were prepared in bottles of $3 \mathrm{~cm}$ diameter and drops of dry yeast in suspension were poured on each medium as food for the developing larvae.

\section{Experimental results}

\section{The environmental effects on curled expressivity.}

A. The effect of the nutritional condition in the larval stage.

1. Pattern of changes in curled expressivity depending on the date of emergence.

Five pairs of curled flies were allowed to breed in each of 15 culture bottles for about one week. The experiments were conducted at $24 \pm 1^{\circ} \mathrm{C}$. All the flies that emerged were counted, and curled expressivity was enumerated by means of the

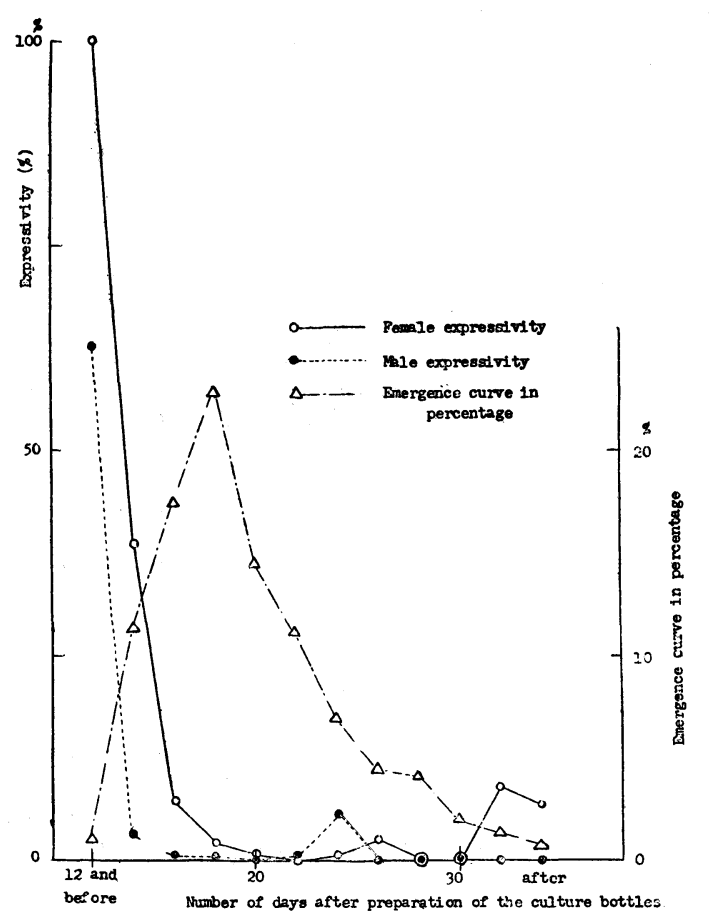

Fig. 1. Changes in curled expressivity with relation to the date of emergence. above method. These examinations were made every other day from the beginning to the end of emergence without regard to the mixture of individuals of the next generation.

Changes in curled expressivity of all the adult flies through the course of emergence are shown in Figure 1. The total number of flies counted was 1506. Curled expressivity was proved to be nearly always higher in the females than in the males. On the first day the expressivity was on a higher level, that is to say, the majority of the emerged flies of both sexes had the typical curled character; then as emergence went on, the flies became more and more normal in appearance, and most of the genotypic curled flies that emerged after about the first week of emergence seemed to be of the wild type phenotypically. Since such a pattern of changes in expressivity depending on the date of emergence was similar to that of Curly character reported previously, the author considered that curled expressivity might be also affected by the nutritional condition in the larval stage.

2. The relation to the quantity of yeast.

To verify the effect of the nutritional condition in the larval stage, the following additional experiments were carried out. Five pairs of curled parents were allowed to breed in the culture media which were prepared for the satiation test: dry yeast and water were supplied to the culture media every day so that the 
larvae would be sated with food. The curled expressivity of both sexes and the body weight of the male flies which emerged from these culture bottles were compared with those from the ordinary culture bottles in which two drops of $5 \%$ suspension of dry yeast had been poured immediately after preparation of the culture media.

Table 1 represents the comparison which shows clearly that a sufficient supply of food is effective in maintaining high level of expressivity of curled flies, and that

Table 1 The relation between the quantity of yeast and curled expressivity

\begin{tabular}{c|c|c|cc|c}
$\begin{array}{c}\text { Experimental } \\
\text { series }\end{array}$ & $\begin{array}{c}\text { Number of } \\
\text { bottles }\end{array}$ & $\begin{array}{c}\text { Number of } \\
\text { emerged flies } \\
\text { per bottle }\end{array}$ & Curled expressivity & $\begin{array}{c}\text { Mean body } \\
\text { weight of the } \\
\text { males (mg.) }\end{array}$ \\
\hline Ordinarily cultured & 15 & 100.4 & 8.0 & 1.7 & 0.68 \\
sated with food & 10 & 96.8 & 99.2 & 61.8 & 0.96 \\
\hline
\end{tabular}

the mean body weight of the male flies and curled expressivity show positive correlation.

These two experiments furnished a support for the conclusion that the nutritional condition during the larval stage is one of the important controlling factors in determining curled expressivity in the adult flies.

\section{B. The effect of cultural temperature.}

Since the nutritional control in the larval stage on curled expressivity gave the same result as on Curly, the author investigated the effect of a second factor, i. e. temperature, on curled character by means of the techniques which had been employed in the experiments on Curly expressivity.

Five pairs of curled flies were allowed to breed in a culture medium at $24 \pm$ $1^{\circ} \mathrm{C}$. in which was poured one drop of $5 \%$ suspension of dry yeast; then the offsprings were transfered to other bottles kept at $19 \pm 1^{\circ} \mathrm{C}$. or $29 \pm 1^{\circ} \mathrm{C}$, when they arrived at the following stages of development:

i) The stage of pupation: about 105 hours after egg-hatching.

ii) The stage of eye-pigmentation: about 145 hours after egg-hatching.

iii) The stage of wing-pigmentation: about 170 hours after egg-hatching.

iv) The stage when the adult flies immediately after emergence had not yet wings begun extension: about 195 hours after egg-hatching.

Figure 2 is a summary of the data for curled expressivity of the adult flies in each experimental series. These results show that high temperature is effective to give higher expressivity of curled character and the temperature-effective period is in the last day of the pupal stage. On the other hand, since the adult flies showed a very low level of curled expressivity even in normal temperature, no significant difference in the expressivities between the adult populations which developed at $19 \pm 1^{\circ} \mathrm{C}$. and at $24 \pm 1^{\circ} \mathrm{C}$. was recognized.

It can be said, therefore, that the patterns of changes of curled expressivity 
are identical with those of Curly character, although the level of expressivity is far lower in the former.

One additive fact must be specifically recorded: namely, that the pleiotropic effects of curled gene, i. e. the erection of postscutelar bristles and the darkening of the body color, were neither influenced by the nutritional condition in the larval stage nor by the temperature conditions in the pupal stage.

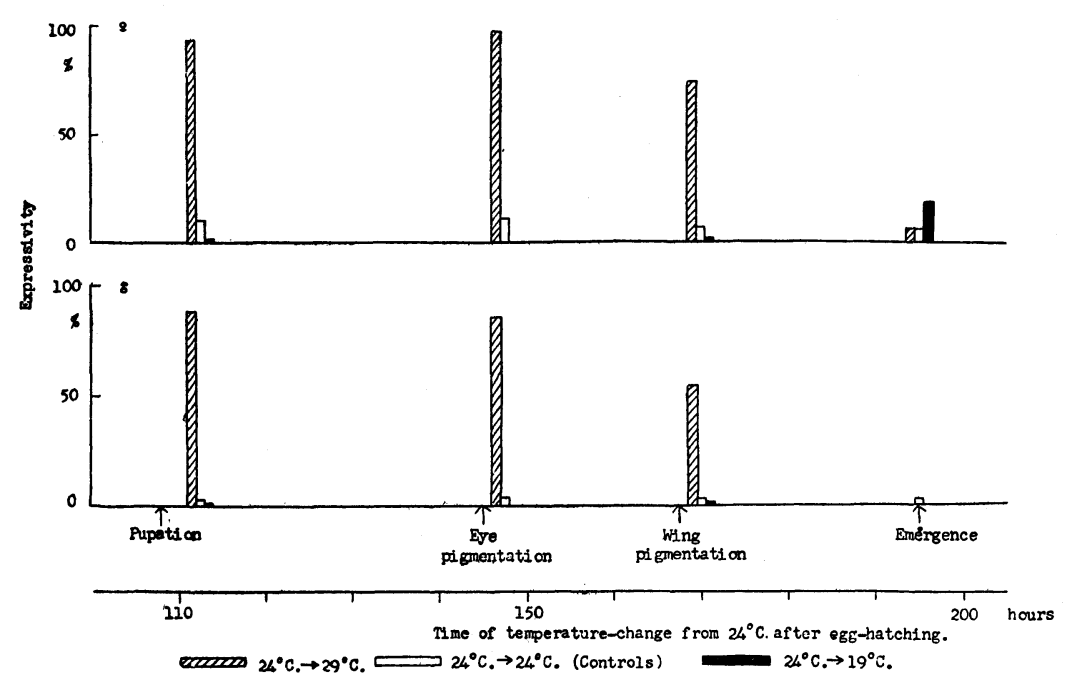

Fig. 2. Result of experiments to determine the temperatureeffective period. Positions of the groups of three histograms show times of temperature-change from $24^{\circ} \mathrm{C}$ after egg-hatching. The detailed explanations are in text.

\section{The interaction between curled and curly genes.}

$A$. Since the similarity of the patterns of changes of curled and Curly expressivities in some environmental conditions was revealed, the author investigated the interaction between these genes. From the laboratory stocks of curled $(\mathrm{cu} / \mathrm{cu})$ and Curly $(\mathrm{Cy} / l)$ the combined stock of curled and Curly $(\mathrm{Cy} / l ; \mathrm{cu} / \mathrm{cu})$ was established by means of a balancer, Stubble $(\mathrm{Sb})$, in the third chromosome.

Five pairs of the parents of $\mathrm{Cy} / l ;+/+,+/+; \mathrm{cu} / \mathrm{cu}$ and $\mathrm{Cy} / l ; \mathrm{cu} / \mathrm{cu}$ were allowed to breed separately in the ordinary culture bottles. Each experimental series was again divided into three groups according to temperatures in the pupal stage, $29 \pm$ $1^{\circ} \mathrm{C}$., $24 \pm 1^{\circ} \mathrm{C}$, and $19 \pm 1^{\circ} \mathrm{C}$. The degrees of the curling appearance of the adult populations were compared. Table 2 presents the results, showing that combination of curled and Curly genes is effective to increase the wing-curling appearance of the adult flies.

$B$. From the result of the above experiment, the author sought further to determine whether the recessive curled gene in the heterozygous state was effective or not in increasing the wing-curling appearance of Curly individuals. Five pairs of $\mathrm{Cy} / l ; \mathrm{Sb} / \mathrm{cu}$ parents were allowed to breed and the curling appearances of $\mathrm{Cy} / l ; \mathrm{Sb} /$ 
Table 2 Degrees of curling appearances of $\mathrm{Cy} / l ;+/+,+/+; \mathrm{cu} / \mathrm{cu}$ and $\mathrm{Cy} / l ; \mathrm{cu} / \mathrm{cu}$ genotypes.

\begin{tabular}{|c|c|c|c|c|c|c|}
\hline \multirow[t]{2}{*}{ Temperature } & \multicolumn{2}{|c|}{$\mathrm{Cy} / l ;+1+$} & \multicolumn{2}{|c|}{$+1+; \mathrm{cu} / \mathrm{cu}$} & \multicolumn{2}{|c|}{$\mathrm{Cy} / l ; \mathrm{cu} / \mathrm{cu}$} \\
\hline & $\begin{array}{l}\text { Number } \\
\text { of } \\
\text { bottles }\end{array}$ & $\begin{array}{c}\text { Number of } \\
\text { emerged } \\
\text { flies per } \\
\text { bottle }\end{array}$ & $\begin{array}{l}\text { Number } \\
\text { of } \\
\text { bottles }\end{array}$ & $\begin{array}{c}\text { Number of } \\
\text { emerged } \\
\text { flies per } \\
\text { bottle }\end{array}$ & $\begin{array}{l}\text { Number } \\
\text { of } \\
\text { bottles }\end{array}$ & $\begin{array}{l}\text { Number of } \\
\text { emerged } \\
\text { flies per } \\
\text { bottle }\end{array}$ \\
\hline $29 \pm 1^{\circ} \mathrm{C}$ & 5 & 124.8 & 10 & 65.1 & 5 & 66.6 \\
\hline $24 \pm 1^{\circ} \mathrm{C}$ & 5 & 244.6 & 5 & 165.8 & 5 & 133.4 \\
\hline \multirow[t]{3}{*}{$19 \pm 1^{\circ} \mathrm{C}$} & 5 & 179.6 & 5 & 131.4 & 5 & 85.2 \\
\hline & \multicolumn{2}{|c|}{ Degree of curling } & \multicolumn{2}{|c|}{ Degree of curling } & \multicolumn{2}{|c|}{ Degree of curling } \\
\hline & ㅇ & $\hat{o}$ & ㅇ & $\hat{o}$ & ㅇ & $\hat{o}$ \\
\hline $29 \pm 1^{\circ} \mathrm{C}$ & 100.0 & 99.5 & 63.6 & 37.3 & 100.0 & 100.0 \\
\hline $24 \pm 1^{\circ} \mathrm{C}$ & 79.0 & 40.6 & 14.0 & 4.6 & 100.0 & 100.0 \\
\hline $19 \pm 1^{\circ} \mathrm{C}$ & 30.6 & 6.2 & 4.2 & 2.8 & 100.0 & 100.0 \\
\hline
\end{tabular}

$\mathrm{cu}$ and $\mathrm{Cy} / \mathrm{l}$; $\mathrm{cu} / \mathrm{cu}$ offsprings were measured. On the other hand, in order to examine the influence of the $\mathrm{Sb}$ chromosome, five pairs of $\mathrm{Cy} / l ; \mathrm{Sb} /+$ flies were allowed to breed and the curling appearances of $\mathrm{Cy} / l ; \mathrm{Sb} /+$ and $\mathrm{Cy} / l ;+/+$ offsprings were measured. Each experimental series was divided into three groups according to temperature in the pupal stage, $29 \pm 1^{\circ} \mathrm{C}$., $24 \pm 1^{\circ} \mathrm{C}$., and $19 \pm 1^{\circ} \mathrm{C}$.

Table 3 The influences of the chromosomes carrying $\mathrm{Sb}$ and/or $\mathrm{cu}$ on curling appearance of $\mathrm{Cy} / l$ flies

\begin{tabular}{|c|c|c|c|c|c|c|c|c|}
\hline \multirow{2}{*}{$\begin{array}{l}\text { Tempe- } \\
\text { rature }\end{array}$} & \multicolumn{2}{|c|}{$\mathrm{Cy} / l ;+1+$} & \multicolumn{2}{|c|}{$\mathrm{Cy} / l ; \mathrm{Sb}_{l}^{\prime}+$} & \multicolumn{2}{|c|}{$\mathrm{Cy} / l ; \mathrm{Sb} / \mathrm{cu}$} & \multicolumn{2}{|c|}{$\mathrm{Cy} / l ; \mathrm{cu} / \mathrm{cu}$} \\
\hline & $\begin{array}{c}\text { Number } \\
\text { of } \\
\text { bottles }\end{array}$ & $\begin{array}{c}\text { Number of } \\
\text { emerged } \\
\text { flies per } \\
\text { bttle }\end{array}$ & $\begin{array}{c}\text { Number } \\
\text { of } \\
\text { bottle }\end{array}$ & $\begin{array}{c}\text { Number of } \\
\text { emerged } \\
\text { flies per } \\
\text { bottle }\end{array}$ & $\begin{array}{c}\text { Number } \\
\text { of } \\
\text { bottle }\end{array}$ & $\begin{array}{l}\text { Number of } \\
\text { emerged } \\
\text { flies per } \\
\text { bottle }\end{array}$ & $\begin{array}{l}\text { Number } \\
\text { of } \\
\text { bottles }\end{array}$ & $\begin{array}{l}\text { Number of } \\
\text { emerged } \\
\text { flies per } \\
\text { bottle }\end{array}$ \\
\hline $29 \pm 1^{\circ} \mathrm{C}$ & 5 & 33.4 & 5 & 55.4 & 5 & 44.6 & 5 & 1.8 \\
\hline $24 \pm 1^{\circ} \mathrm{C}$ & 5 & 80.0 & 5 & 149.2 & 5 & 157.0 & 5 & 17.8 \\
\hline \multirow[t]{3}{*}{$19 \pm 1^{\circ} \mathrm{C}$} & 5 & 52.5 & 5 & 106.4 & 5 & 103.0 & 5 & 25.6 \\
\hline & \multicolumn{2}{|c|}{ Degree of curling } & \multicolumn{2}{|c|}{ Degree of curling } & \multicolumn{2}{|c|}{ Degree of curling } & \multicolumn{2}{|c|}{ Degree of curling } \\
\hline & ㅇ & $\hat{o}$ & o & $\hat{o}$ & 우 & $\hat{o}$ & q & $\hat{\delta}$ \\
\hline $29 \pm 1^{\circ} \mathrm{C}$ & 100.0 & 100.0 & 100.0 & 100.0 & 100.0 & 100.0 & 100.0 & 100.0 \\
\hline $24 \pm 1^{\circ} \mathrm{C}$ & 66.4 & 20.0 & 84.0 & 47.0 & 100.0 & 98.5 & 100.0 & 100.0 \\
\hline $19 \pm 1^{\circ} \mathrm{C}$ & 10.6 & 9.2 & 37.5 & 8.7 & 85.7 & 40.1 & 100.0 & 100.0 \\
\hline
\end{tabular}

Comparison of the degree of curling appearance of the adult populations of each genotype is presented in Table 3. In this table it is recognized that curled heterozygotes show curling appearance intermediate between both homozygotes; that is, one dose of recessive curled gene is effective in increasing the curling appearance of a Curly individual; in other words, a curled gene is incompletely dominant in the presence of a Curly gene. In addition, it is presumed from the 
comparison between $\mathrm{Cy} / l ;+/+$ and $\mathrm{Cy} / l ; \mathrm{Sb} /+$ that the chromosome carrying the $\mathrm{Sb}$ gene has one or more modifying genes which are effective in increasing the expressivities of curled and/or Curly characters.

\section{Discussion}

This study clarified the fact that the expression of the dominant Curly gene in the second chromosome and of the recessive curled gene in the third chromosome are influenced in the same manner by the nutritional conditions in the larval stage and the temperature conditions in the pupal stage, although the expressivity of curled character is of lower level than that of Curly character. That is to say, these two genes mimic to one another not only in their phenotypes but also in their patterns of change in the phenotypes depending on some environmental factors. Moreover, when these mimic genes are combined, the wing-curling appearances of the adult flies change increasingly. From these results and from the fact that the pleiotropic effects of the curled gene are not influenced by these environmental factors, it may be presumed that the physical or chemical bases of the wing-curling effects of Curly and curled genes are common, although the effect may be greater in the former than in the latter.

The fact that the curled gene is completely recessive is considered to mean that certain threshold for the manifestation of wing-curling phenotype may be transcended only in the homozygous state of this gene. If the assumption is accepted that the material bases of the expression of Curly and curled genes are common, the phenomenon that the curled gene when combined with the Curly acts as an incompletely dominant gene on the higher level of expressivity can be interpreted by the hypothesis that the existence of the Curly gene raises the level of wing-curling expressivity and allows it to transcend such a threshold.

\section{Summary}

1. The expressivity of curled character in Drosophila melanogaster is influenced by the environmental conditions. One of these is the nutritional condition through the larval stage: the better the nutritional condition the more typical the curled character. Another is the cultural temperature: the higher the temperature the higher the expressivity. The temperature-effective period is in the last day of the pupal stage. These properties of the curled phenotype are identical with those of Curly character, although the level of expressivity is far lower in the former.

2. When these two mimic genes are combined, the curling appearance of the flies changes increasingly; the recessive curled gene is incompletely dominant in the presence of the Curly gene.

\section{Acknowledgement}

The author wishes to acknowledge to Dr. D. Moriwaki, Tokyo Metropolitan University, for his kindness in the preparation of the manuscript. The author is also grateful to Prof. K. Masui and Assist. Prof. K. Kondo for their constructive criticisms.

\section{Literature cited}

Nozawa, K. 1956. The effects of the environmental conditions on Curly expressivity in Drosophila melanogaster. Jap. Jour. Genet. $31: 163-171$. 